\title{
DEVELOPMENT AND VALIDATION OF CONFIRMATORY METHOD FOR ANALYSIS OF NITROFURAN METABOLITES IN MILK, HONEY, POULTRY MEAT AND FISH BY LIQUID CHROMATOGRAPHY-MASS SPECTROMETRY
}

\author{
Fatih Alkan ${ }^{1}$, Arzu Kotan ${ }^{1}$, Nurullah Ozdemir ${ }^{2}$ \\ ${ }^{1}$ Pendik Veterinary Control Institute, Department of Pharmacology, \\ Laboratory of Residue. 34890 Pendik, Istanbul, Turkey \\ ${ }^{2}$ Namik Kemal University, Veterinary Faculty, Department of Pharmacology and \\ Toxicology, Degirmenalti Mevkii, 59030 Tekirdag, Turkey
}

Received 21 May 2015; Received in revised form 15 July 2015; Accepted 2 September 2015

\begin{abstract}
In this study we have devoloped and validated a confirmatory analysis method for nitrofuran metabolites, which is in accordance with European Commission Decision 2002/657/EC requirements. Nitrofuran metabolites in honey, milk, poultry meat and fish samples were acidic hydrolised followed by derivatisation with nitrobenzaldehyde and liquid-liquid extracted with ethylacetate. The quantitative and confirmative determination of nitrofuran metbolites was performed by liquid chromatography/electrospray ionisation tandem mass spectrometry (LC/ESI-MS/MS) in the positive ion mode. In-house method validation was performed and reported data of validation (specificity, linearity, recovery, $\mathrm{CC}_{\alpha}$ and $\mathrm{CC}_{\beta}$ ). The advantage of this method is that it avoids the use of clean-up by Solid-Phase Extraction (SPE). Furthermore, low levels of nitrofuran metabolites are detectable and quantitatively confirmed at a rapid rate in all samples.
\end{abstract}

Key words: fish, honey, LC-MS/MS, milk, nitrofuran metabolites, poultry meat

\section{INTRODUCTION}

Nitrofurans are broad spectrum antibacterial agents known as Schiff's bases, which are derivates of nitrofuraldehyde. In veterinary medicine, it were used in the treatment of gastrointestinal and dermatological infections in beef, pork, poultry, fish and shrimp, and also applied as a contribution to the systemic and feed as growth promoters. In addition, nitrofurans were used in the treatment of bacterial infections in bee colony health (1).

Nitrofurans have been prohibited from use in food-producing animals in the European Union

Corresponding author: Assist. Prof. Nurullah Ozdemir, $\mathrm{PhD}$ E-mail address: nozdemir@nku.edu.tr

Present address: University of Namik Kemal, Faculty of Veterinary

Medicine, Department of Pharmacology and Toxicology

59030 Tekirdag, Turkey

Phone: +902822504719 , Fax: +902822509960

Copyright: (C) 2015 Ozdemir N. This is an open-access article published under the terms of the Creative Commons Attribution License which permits unrestricted use, distribution, and reproduction in any medium, provided the original author and source are credited.

Competing Interests: The authors have declared that no competing interests exist.

Available Online First: 4 November 2015

Published on: 15 March 2016

http://dx.doi.org/10.1515/macvetrev-2015-0060 and most countries due to public health and safety concerns, particularly in relation to the carcinogenic potential of either the parent compounds or their metabolites (2). The use of nitrofurans in foodproducing animal was prohibited in Turkey (3).

A minimum required performance limit (MRPL) for nitrofurans is set in European Union for the metabolites in poultry meat and aquaculture products at the level of $1 \mu \mathrm{g} \mathrm{kg}^{-1}$ for all metabolites (4).

Analytically, residues are checked only for marker metabolites of the 4 nitrofuran chemicals, in particular: 3-amino-2-oxazolidinone (AOZ) for furazolidone, 3-amino-5-methylmorpholino2-oxazolidinone (AMOZ) for furaltadone, 1-aminohydantoin (AHD) for nitrofurantoin and semicarbazide (SEM) for nitrofurazone (5).

Several methods have been reported in the analysis of nitrofuran metabolite in food samples. These include thin-layer chromatography (TLC) (6), high performance liquid chromatography diode-array detector (HPLC DAD) (7) and UV detector $(8,9)$, liquid chromatography-mass 
spectrometry (LC-MS/MS) $(10,11,12)$. LC-MS/MS analyses were considered very sensitive and commonly used the confirmatory analysis.

In the current study, a method was devoloped and validated for quick confirmatory analysis of nitrofuran metabolites (AOZ, AMOZ, AHD and SEM). All samples were acidic hydrolised followed by derivatisation with nitrobenzaldehyde and liquid-liquid extracted with ethylacetate. The quantitative and confirmatory determination of nitrofuran metabolites was performed by liquid chromatography/electrospray ionisation tandem mass spectrometry (LC/ESI-MS/MS) in the positive ion mode.

\section{MATERIAL AND METHODS}

\section{Reagents and standards}

3-amino-2-oxazolidinone (AOZ), 1-aminohydantoin (AHD), AMOZ-d5, $\quad\left(\mathrm{C}^{13}\right)_{3}-\mathrm{AHD}, \quad \mathrm{C}^{13} \mathrm{~N}^{15}-\mathrm{N}^{15}-$ SEM, 2NP-AOZ, 2NP-AMOZ, 2NP-AHD and 2-nitrobenzaldehyde (2-NBA), 3-amino-5morpholinomethyl-2-oxazolidinon (AMOZ), semicarbazide hydrochloride (SEM), AOZ-d4, 2NP-AOZ-D4, 2NP-AMOZ-D5, 2NP-( $\left.\mathrm{C}^{13}\right)_{3}-\mathrm{AHD}$ and $2 \mathrm{NP}-\mathrm{C}^{13} \mathrm{~N}^{15}-\mathrm{N}^{15}-\mathrm{SEM}$ were obtained from Dr. Ehrenstorfer and Witega. The purity of all compounds was greater than $99 \%$.

Methanol $(\mathrm{MeOH})$ and ethylacetate (LC grade), hydrochloric acid $(\mathrm{HCl})$, dimethylsulphoxide (DMSO), $n$-hexane and potassium hydrogen phosphate were supplied by Merck. The water was purified with a from a Milli-Q purifying system (Elga PureLab Prima).

Individual standart stock solutions of $1 \mathrm{mg} / \mathrm{mL}$ were prepared in methanol, but SEM was prepared in DMSO. Working solutions of $10 \mathrm{ng} / \mathrm{mL}$ were diluted by methanol. All standard stock soutions were stored $-20^{\circ} \mathrm{C}$, and the working solutions were stored in refrigerator.

The concentration and content of mix standard solution were used to spiked samples with AMOZ, AOZ, AHD and SEM at a 8, 16, 20 and $20 \mathrm{ng} / \mathrm{mL}$ respectively. The concentration and content of internal mix standard solutions were used AOZ-d4, AMOZ-d5, $\left(\mathrm{C}^{13}\right)_{3}$-AHD and $\mathrm{C}^{13} \mathrm{~N}^{15}-\mathrm{N}^{15}$-SEM at a 40, 40, 100 and $100 \mathrm{ng} / \mathrm{mL}$, respectively.

\section{Sample preparation}

Collected samples for validation were known to be negative in the screning analysis within the national program for residues control in Turkey. Only, the milk samples were centrifuged at $3500 \mathrm{~g}$, $+4^{\circ} \mathrm{C}, 15 \mathrm{~min}$ and upper the fat layer was removed before extraction.
Two grams or $2 \mathrm{~mL}$ homogenised samples (milk, honey, poultry meat and fish) were weighed into $50 \mathrm{~mL}$ polypropylene centrifuge tubes. Standard spiking solution mix $(50,100,150$ and $200 \mu \mathrm{L})$, internal standard solution mix $(100 \mu \mathrm{L})$ and $5 \mathrm{~mL}$ of $0.1 \mathrm{M} \mathrm{HCl}$ were added. The extraxtion tube was shaken for $2 \mathrm{~min}$ by vortex. 2-nitrobenzaldehyde (2-NBA) $(50 \mathrm{mM}, 300 \mu \mathrm{L})$ were added and the mixture shaken for $2 \mathrm{~min}$ by vortex. The tube were capped and incubated overnight $(16 \mathrm{~h})$ in the $37^{\circ} \mathrm{C}$ temperature. After derivatization, the samples were cooled in room temperature and neutralized by addition $1 \mathrm{~mL}$ of $1 \mathrm{M} \mathrm{K}_{2} \mathrm{PO}_{4}$ and mixed for $2 \mathrm{~min}$ by vortex. Ethylacetate $(5 \mathrm{~mL})$ and $\mathrm{n}$-hexane $(3 \mathrm{~mL}$ ) was added and mixed for $15 \mathrm{~min}$ by vortex and centrifuged at $4000 \mathrm{~g}$ for $15 \mathrm{~min}$. The organic phase $(6 \mathrm{~mL})$ was collected into a $15 \mathrm{~mL}$ graduated glass tubes. The organic fraction was evaporated to dryness under a stream of nitrogen in a water bath at $42^{\circ} \mathrm{C}$.

The dry residue was reconstituted with n-hexane $(2 \mathrm{~mL})$ and mixed for $2 \mathrm{~min}$ by vortex and methanol/ water $(5 / 95)(0.7 \mathrm{~mL})$ was added and mixed for $2 \mathrm{~min}$ by vortex. $0.5 \mathrm{~mL}$ samples were taken from the lower phase with the help of syringe or automatic pipette and filtered using a $0.2 \mu \mathrm{m}$ syringe filter into an autosampler vial.

\section{Instrumentation}

Chromatographic analyses were performed on a LC-MS/MS equipment consisted of a Thermo Electron TSQ Quantum Access Max, mass spectrometer controlled by the Xcalibur (2.2 SP1) software.

Chromatographic separations were achieved on Phenomenex Synergy Hydro RP (150x2.00 mm $80 \AA 4 \mu \mathrm{m})$, protected with a C18 guard column. The mobile phase was deionised water/methanol (80/20) (A) and methanol acidified with $0.1 \%$ acetic acid. The linear gradient was: $0-2 \min 100 \% \mathrm{~A}$, 2-9 $\min 10 \% \mathrm{~A}$ and $9-15 \mathrm{~min} 100 \% \mathrm{~A}$ and flow rate of $0.25 \mathrm{~mL} / \mathrm{min}$. Injection volume was $50 \mu \mathrm{L}$. The column was thermostated at $40^{\circ} \mathrm{C}$. The analysis of samples were carried in the positive ESI-MS-MS ion mode.

\section{Mass spectrometry}

MS/MS parameters and precursor-product ions of each compound were tuned by direct infusion in the SRM mode and $0.25 \mathrm{~mL} / \mathrm{min}$ flow rate of the mobile phase A and B) (50:50).

The concentration and content of mix standards derivatizes and internal standards used for control of the MS-detector, were $25 \mu \mathrm{g} \mathrm{kg}^{-1}$ for 2-NP-SEM-C ${ }^{13} \mathrm{~N}^{15}-\mathrm{N}^{15}$ and 2-NP- $\left(\mathrm{C}^{13}\right)_{3}-\mathrm{AHD}$ and other standards at $10 \mu \mathrm{g} \mathrm{kg}^{-1}$. 
Analysis of nitrofuran metabolites in milk, honey, poultry meat and fish by LC-MS

MS/MS detector parameters are given in Table 1. The precursor-product ions of each compound and their collision energy are given in Table 2 .

Table 1. MS detector parameters

\begin{tabular}{ll}
\hline Ionization Mode & ESI + \\
Spray Voltage & 3000 \\
Vaporizer Temperature & $300{ }^{\circ} \mathrm{C}$ \\
Capillary Temperature & $300{ }^{\circ} \mathrm{C}$ \\
Sheath Gas & $35 \mathrm{psi}$ \\
Ion Sweep Gas & $0,5 \mathrm{psi}$ \\
Aux Gas & $15 \mathrm{psi}$ \\
Skimmer Offset & 3 \\
Q2 CID Gas & $1,3 \mathrm{psi}$ \\
Data Proses & 5 \\
Mass peak width in amu & Q1 $=0,7$ \\
\hline
\end{tabular}

\section{RESULTS}

\section{Specificity/Selectivity}

Specificity/selectivity were evaluated via analysis of blank matrix samples fortified with mixed benzimidazole and nitroimidazole standards (concentration of $1 \mu \mathrm{g} \mathrm{kg}^{-1}$ each) and with standards of nitrofuran metabolites. According to analysis no significant peaks with an $\mathrm{S} / \mathrm{N}$ (signal to noise) ratios of 3 or more and chromatographic interference were being observed at the retention times of the targeted nitrofuran metabolites.

\section{Linearity}

The matrix calibration curves were at four levels: 0.4, 0.8, 1.2 and $1.6 \mu \mathrm{g} \mathrm{kg}^{-1}$ for AOZ, AMOZ, AHD and SEM, which is in accordance with the MRPL levels. For each compound we made three matrix calibration curves, using blank samples, over three days with 6 replicates at four concentration levels. No significant differences were found between the different matrix curves $\left(r^{2}>0.9941\right)$ shown in Table 3 .

Table 2. LC-MS/MS confirmation parameters for the analytes

\begin{tabular}{|c|c|c|c|c|c|c|}
\hline Analyte & $\underset{(\mathbf{m} / \mathbf{z})}{\operatorname{MS}}$ & $\begin{array}{c}\text { MS-MS } \\
(\mathbf{m} / \mathbf{z})\end{array}$ & $\begin{array}{c}\text { Collision } \\
\text { Energy }\end{array}$ & Width & Tube Lens & Dwell Time \\
\hline \multirow{3}{*}{ 2-NP-SEM } & & $166.0^{*}$ & 11 & 0,05 & 98 & 0,1 \\
\hline & 209.0 & & & & & \\
\hline & & 192.0 & 13 & 0,05 & 98 & 0,1 \\
\hline 2-NP-SEM-C ${ }^{13} \mathrm{~N}^{15}-\mathrm{N}^{15}$ & 212.0 & 168.0 & 10 & 0,05 & 115 & 0,1 \\
\hline \multirow{3}{*}{ 2-NP-AHD } & & 134.0 & 12 & 0,05 & 71 & 0,1 \\
\hline & 249.0 & & & & & \\
\hline & & $104.1^{*}$ & 22 & 0,05 & 71 & 0,1 \\
\hline 2-NP- $\left(\mathrm{C}^{13}\right)_{3}-\mathrm{AHD}$ & 252.0 & 134.0 & 12 & 0,05 & 71 & 0,1 \\
\hline \multirow{3}{*}{ 2-NP-AOZ } & & 134.0 & 13 & 0,05 & 64 & 0,1 \\
\hline & 236.0 & & & & & \\
\hline & & $104.0^{*}$ & 22 & 0,05 & 64 & 0,1 \\
\hline 2-NP-AOZ-D4 & 240.0 & 133.9 & 12 & 0,05 & 65 & 0,1 \\
\hline \multirow{3}{*}{ 2-NP-AMOZ } & & 291.0 & 12 & 0,05 & 70 & 0,1 \\
\hline & 335.0 & & & & & \\
\hline & & $261.9^{*}$ & 17 & 0,05 & 70 & 0,1 \\
\hline 2-NP-AMOZ-D5 & 340.0 & 296.0 & 12 & 0,05 & 71 & 0,1 \\
\hline
\end{tabular}

*Confirmation ion 


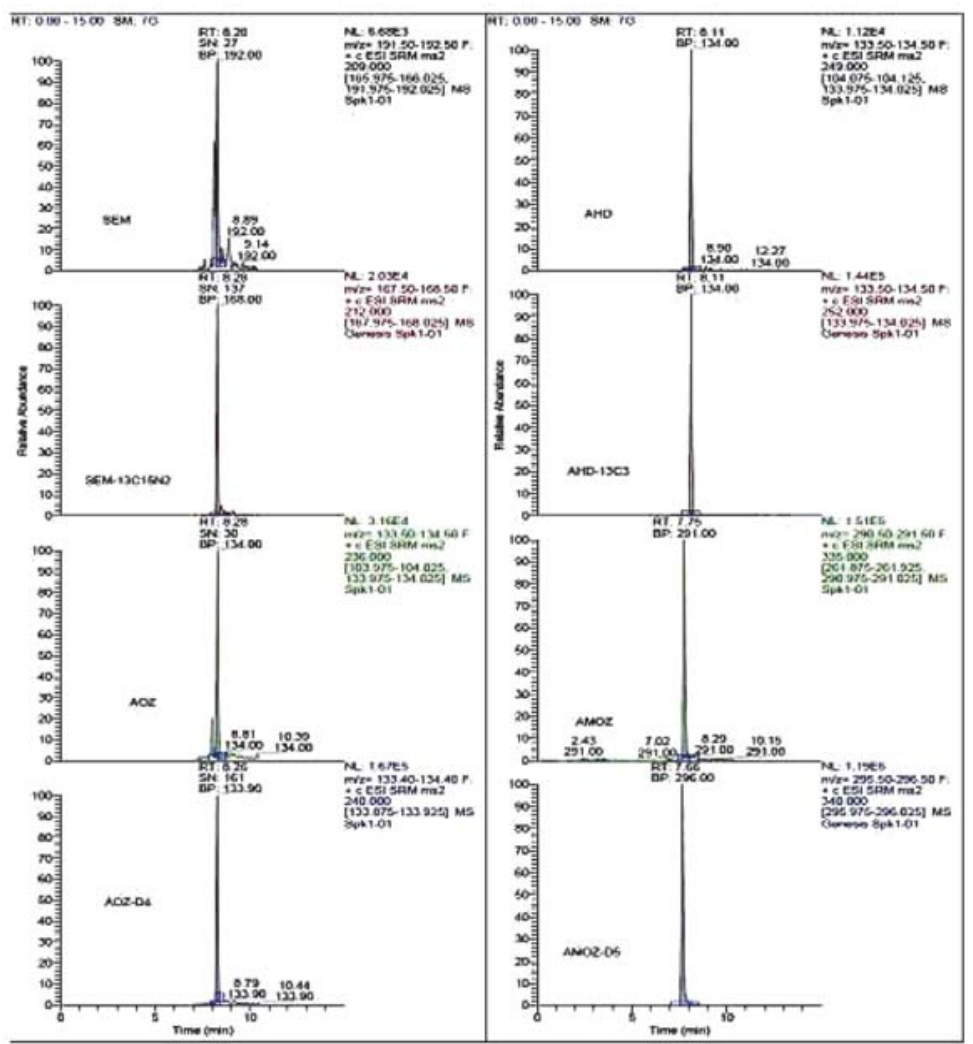

Figure 1. Chromatograms of blank milk samples fortified at $0.2 \mu \mathrm{g} \mathrm{kg}$-1 for AMOZ, $0.3 \mu \mathrm{g} \mathrm{kg}{ }^{-1}$ for AOZ and $\mathrm{AHD}, 0.4 \mu \mathrm{g} \mathrm{kg}^{-1}$ for SEM

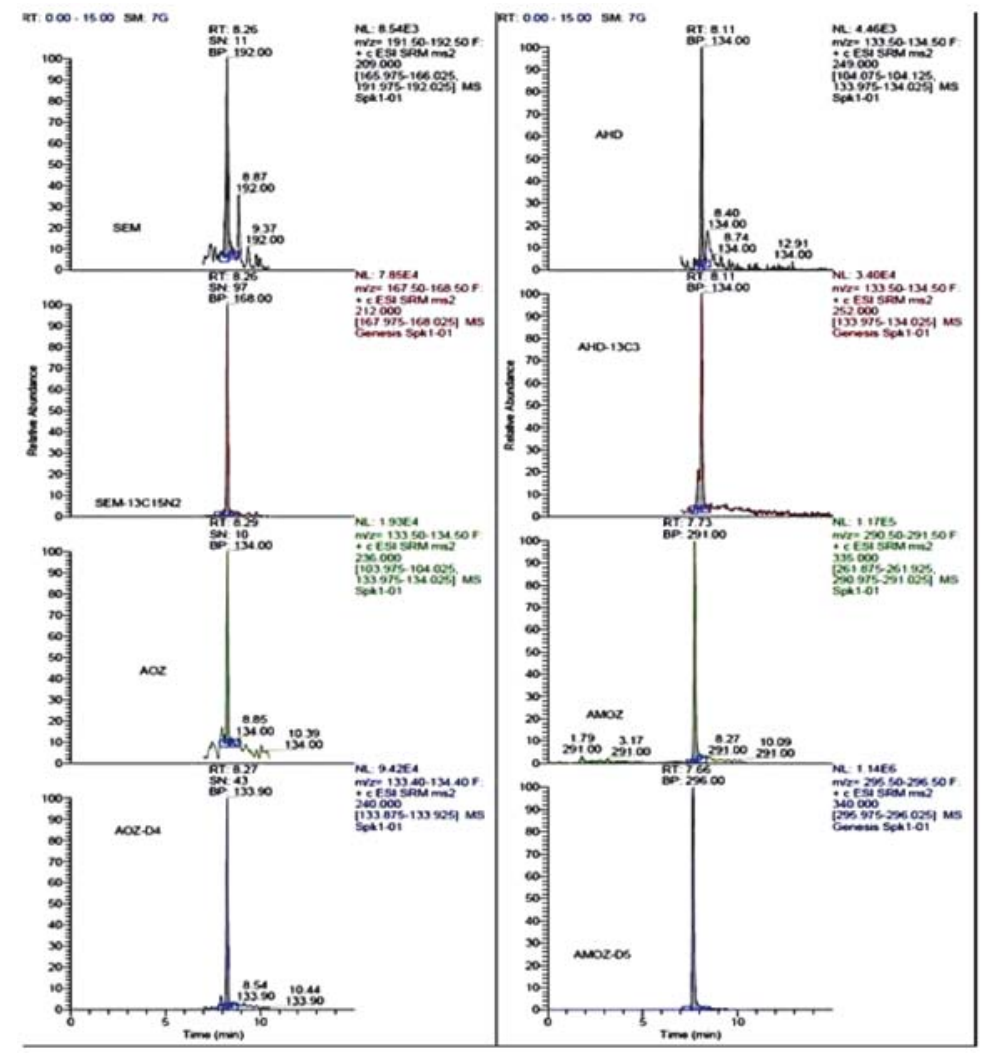

Figure 2. Chromatograms of blank honey samples fortified at $0.2 \mu \mathrm{g} \mathrm{kg} \mathrm{kg}^{-1}$ for AMOZ, $0.4 \mu \mathrm{gg}^{-1}$ for $\mathrm{AOZ}$ and SEM, $0.5 \mu \mathrm{g} \mathrm{kg}^{-1}$ for AHD 
Analysis of nitrofuran metabolites in milk, honey, poultry meat and fish by LC-MS

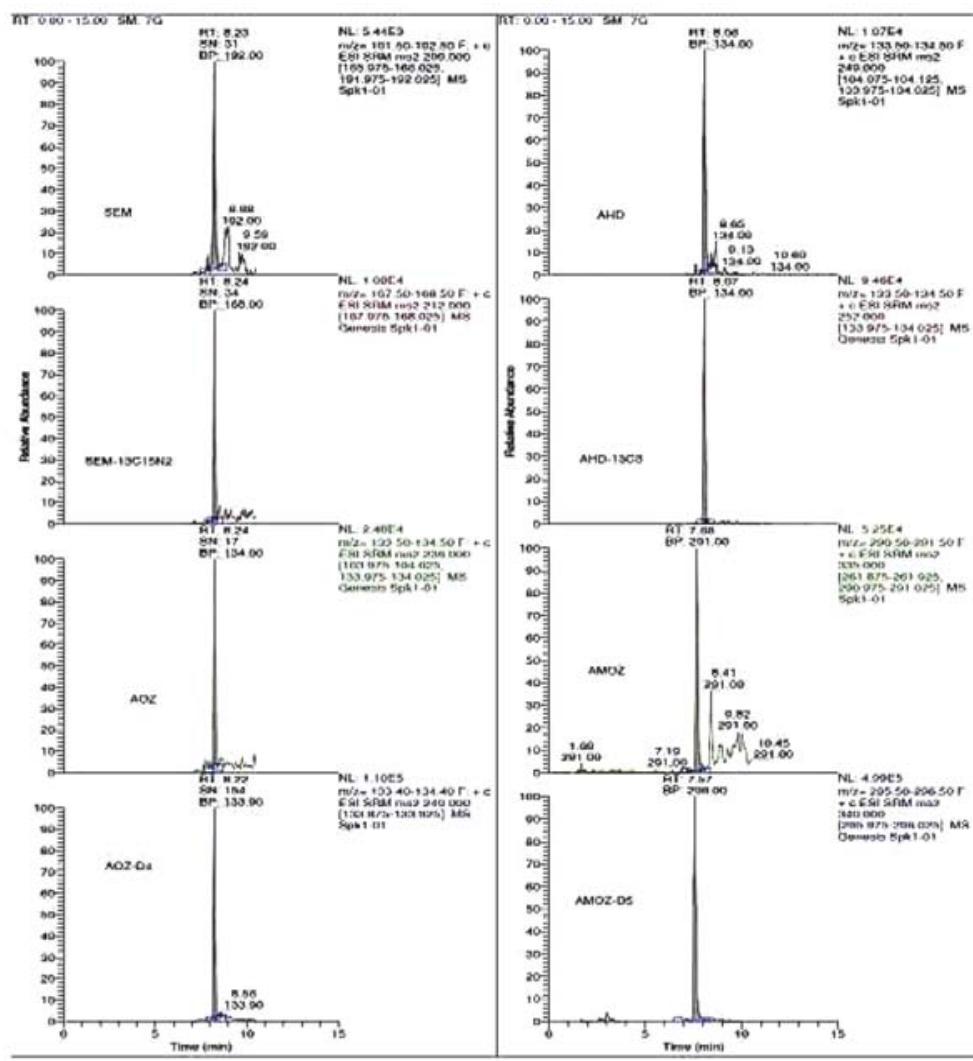

Figure 3. Chromatograms of blank poultry meat samples fortified at $0.2 \mu \mathrm{g} \mathrm{kg}^{-1}$ for AMOZ, $0.4 \mu \mathrm{g} \mathrm{kg}^{-1}$ for AOZ, $0.5 \mu \mathrm{g} \mathrm{kg}^{-1}$ for SEM and AHD

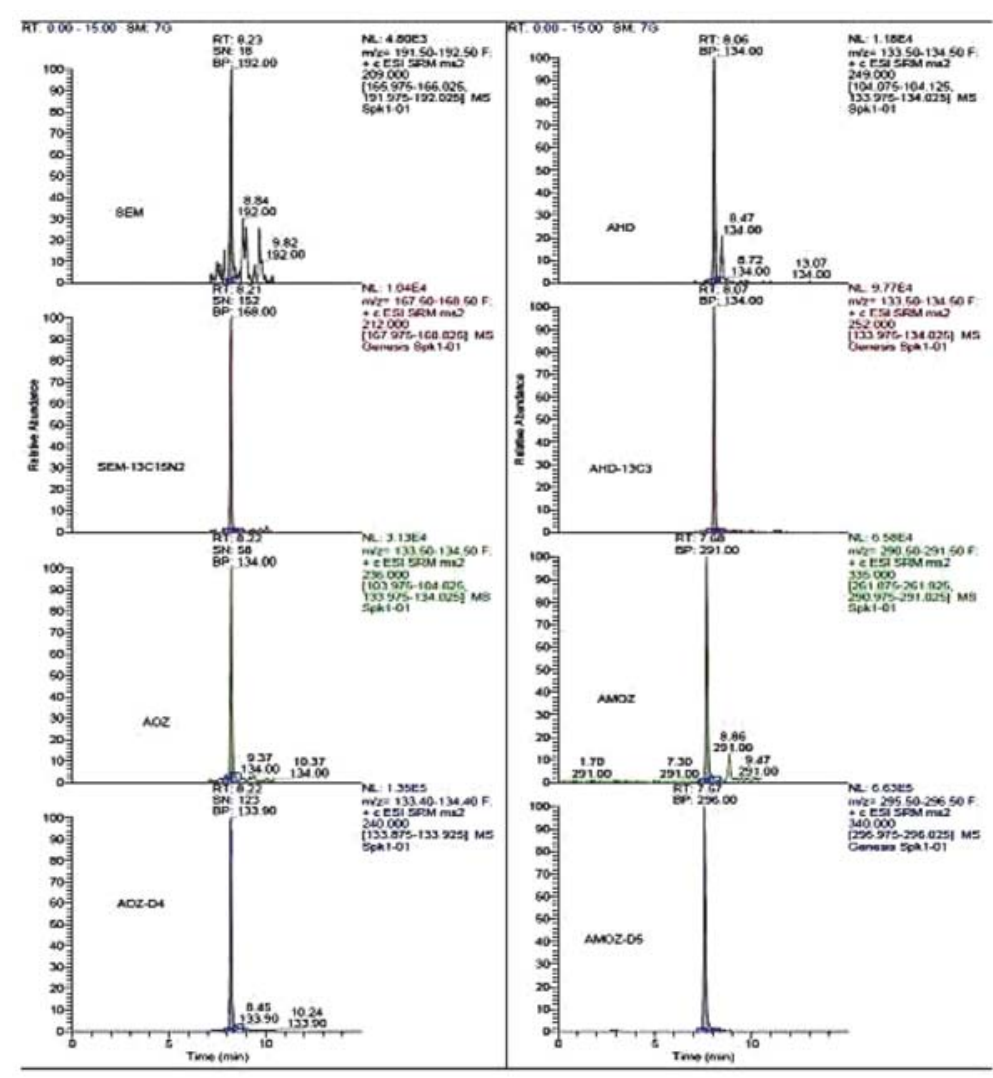

Figure 4. Chromatograms of blank fish samples fortified at $0.2 \mu \mathrm{g} \mathrm{kg}^{-1}$ for AMOZ, $0.4 \mu \mathrm{g} \mathrm{kg}^{-1}$ for AOZ, $0.5 \mu \mathrm{g} \mathrm{kg}^{-1}$ for SEM and AHD 

$\left(C C_{\beta}\right)$

Decision limit ( $\mathrm{CC}$ ) and detection capability

The $\mathrm{CC}_{\alpha}$ and $\mathrm{CC}_{\beta}$ for banned substances were calculated with the application of the following formula;

$\mathrm{CC} \alpha=\mathrm{C}_{1}+2.33 \times \mathrm{SD}_{\mathrm{wIR}}$

where in $\mathrm{C}_{1}$ is lowest concentration level of the validation study (MRPL) and $\mathrm{SD}_{\text {wIR }}$ is the standard deviation from within-laboratory reproducibility.

$\mathrm{CC} \beta=\mathrm{CC} \alpha+1.64 \times \mathrm{SD}_{\mathrm{wIR}, \mathrm{CC} \alpha}$

where in $\mathrm{SD}_{\text {wIR,CCa }}$ is standard deviation at $\mathrm{CC}_{\alpha}$ concentration.

For each compound of $\mathrm{CC}_{\alpha}$ and $\mathrm{CC}_{\beta}$ were calculated from the linearity study. The mean value $\mathrm{CC} \alpha$ and $\mathrm{CC} \beta$ were presented in Table 3 .
ESI-MS conditions. Figure 1, 2, 3 and 4 show LC/ MS/MS extracted-ion chromatograms obtained from analysis of a spiked samples.

This method has been developed and in-house validated in four different matrices (milk, honey, poultry meat and fish) according to the European Commission Decision 2002/657/EC requirements (13). Also, all four matrices have been accredited according to ISO 17025 by TURKAK (Agency of Accreditation in Turkey).

The majority of the method for nitrofuran metabolites in food then employ a solid phase extraction (SPE) step in order clean-up. Barbosa et al. (7), determinated of nitrofurans in animal feeds by liquid chromatography-UV photodiode

Table 3. Summary of Linearity, $\mathrm{CC}_{\alpha}$, and $\mathrm{CC}_{\beta}$

\begin{tabular}{|c|c|c|c|c|c|c|c|c|c|c|c|c|c|}
\hline \multirow{2}{*}{ Analyte } & \multirow{2}{*}{$\begin{array}{c}\text { Calibration } \\
\text { range } \\
\left(\mu g \mathrm{~kg}^{-1}\right)\end{array}$} & \multicolumn{4}{|c|}{ Linearity $\left(r^{2}\right)$} & \multicolumn{4}{|c|}{$\mathbf{C C}_{\alpha}\left(\mu g k^{-1}\right)$} & \multicolumn{4}{|c|}{$\mathbf{C C}_{\beta}\left(\mu g k^{-1}\right)$} \\
\hline & & Honey & Milk & $\begin{array}{c}\text { Poultry } \\
\text { Meat }\end{array}$ & Fish & Honey & Milk & $\begin{array}{c}\text { Poultry } \\
\text { Meat }\end{array}$ & Fish & Honey & Milk & $\begin{array}{c}\text { Poultry } \\
\text { Meat }\end{array}$ & Fish \\
\hline $\mathrm{AOZ}$ & $0.4-1.6$ & 0.999 & 0.998 & 0.994 & 0.997 & 0.44 & 0.33 & 0.45 & 0.45 & 0.46 & 0.35 & 0.48 & 0.48 \\
\hline AMOZ & $0.2-0.8$ & 0.999 & 0.998 & 0.998 & 0.996 & 0.21 & 0.22 & 0.22 & 0.23 & 0.22 & 0.23 & 0.23 & 0.24 \\
\hline AHD & $0.5-2.0$ & 0.998 & 0.999 & 0.995 & 0.996 & 0.54 & 0.34 & 0.56 & 0.59 & 0.57 & 0.37 & 0.60 & 0.65 \\
\hline SEM & $0.4-0.6$ & 0.996 & 0.995 & 0.994 & 0.995 & 0.44 & 0.47 & 0.59 & 0.61 & 0.47 & 0.51 & 0.65 & 0.69 \\
\hline
\end{tabular}

\section{Recovery}

The method recoveries and RSDs were determined from 6 replicates at four concentration levels spiking blank samples over three days. The recovery results were observed in acceptable range of $70-110 \%$. All the data relating to method recovery and precision were summarisedin Table 4; mean recoveries ranging and $\mathrm{CV} \%$ values were satisfactory, required by Decision 2002/657/EC.

\section{Evaluation}

In order to evaluate this method, it eventually participating in the Food Analysis Performance Assessment Scheme (FAPAS), the test of "Nitrofuran Metabolites in Prawns" (FAPAS 02229, 12/05/2014, Lab No:75). AOZ total assigned value were $0.934 \mu \mathrm{g} \mathrm{kg}^{-1}$, the results of our laboratory $0.8 \mu \mathrm{g} \mathrm{kg}^{-1}$. Z-score were -0.7 . The result is good and satisfactory.

\section{DISCUSSION}

To measure nitrofuran metabolites using the selective reaction-monitoring (SRM) mode, full scan and product ion spectra of the analytes were investigated under the LC conditions described in mass Spectrometry section. Nitrofuran metabolites could be detected under positive ionization mode array detection and liquid chromatography-ionspray tandem mass spectrometry. Following ethyl acetate extraction at mild alkaline conditions and purification on $\mathrm{NH}_{2}$ column (SPE), the nitrofurans are determined using liquid chromatography with photodiode-array detection (LC-DAD).

Mottier et al. (11) quantitative determinated of four nitrofuran metabolites in meat by isotope dilution liquid chromatography-electrospray ionisation-tandem mass spectrometry. This study, was used a method liquid-liquid extraction and cleanup on a polymeric solid phase extraction cartridge (SPE) are then performed before LC-MS/MS analysis by positive electrospray ionisation (ESI).

Consequently this LC-ESI-MS-MS method allows the simultaneous determination of nitrofuran metabolites in four matrix. The method avoids the use of clean-up by SPE and could be performed quickly. The obtained validation results indicate the accordance of the method with Decision 2002/657/EC (13). The repeatability and withinlaboratory reproducibility (precision) of the method are less than $9.86 \%$ for all analytes. The $\mathrm{CC}_{\alpha}$ and $\mathrm{CC}_{\beta}$ are below the MRPL of $1 \mu \mathrm{g} \mathrm{kg-1}$. This method has been used for confirmatory analysis of nitrofuran metabolites in honey, milk, poultry meat and fish sample. 


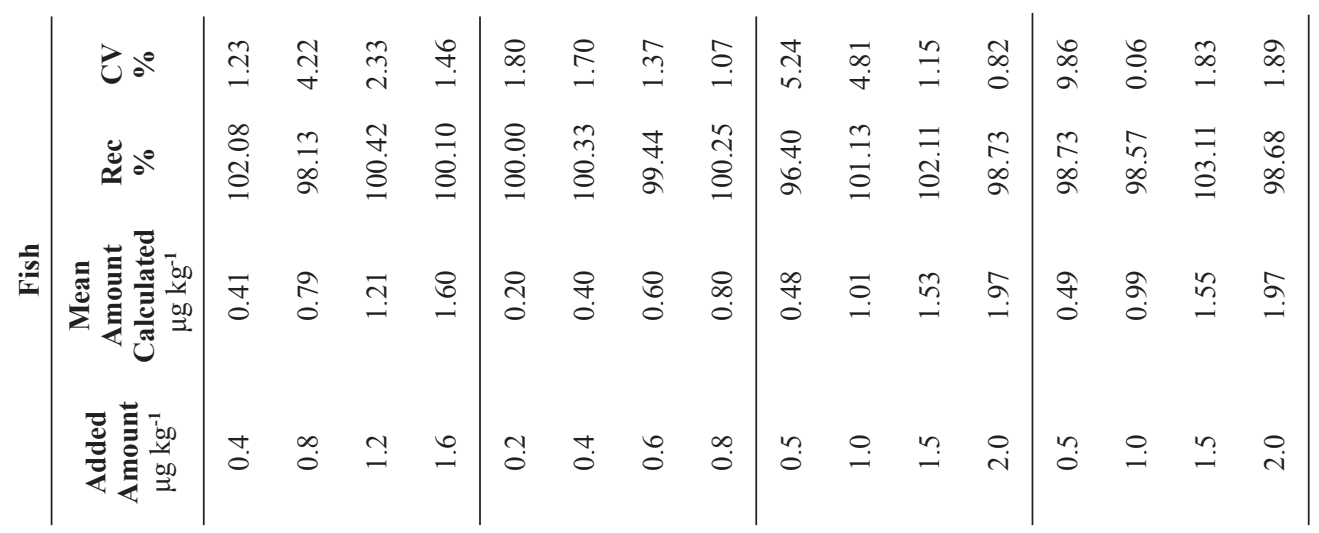

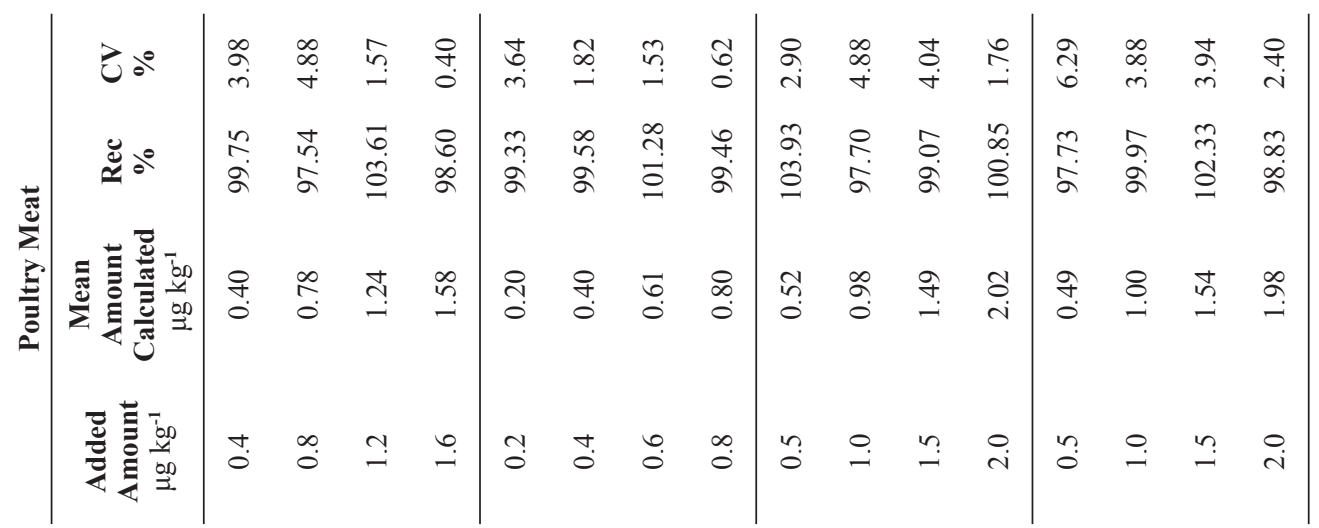

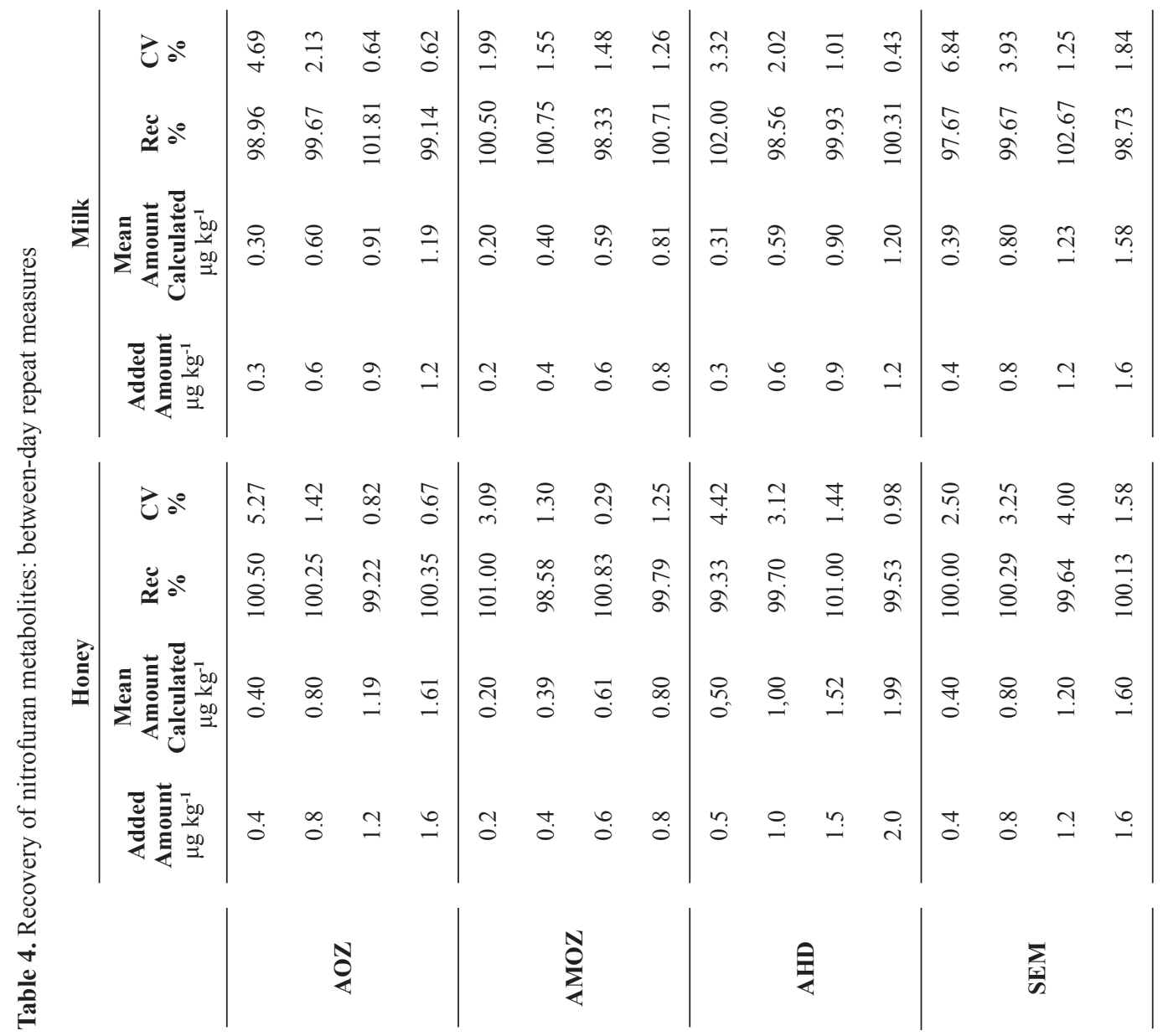




\section{CONCLUSION}

A rapid and sensitive method described in this paper provides reliable, simultaneous quantitative analysis for nitrofuran metabolites residues in milk, honey, poultry meat and fish samples. The optimized procedure provides significant advantages including simplicity, low operation cost, avoids the use of clean-up by SPE.

Thus should be performed quickly confirmative analysis for nitrofuran metabolites residues in milk, honey, poultry meat and fish samples and used as a routine analysis.

\section{REFERENCES}

1. Barbosa J., Ferreira S., Pais A.C., Silveria M.I.N. Ramos F. (2011). Nitrofuran in poultry: use, control and residue analysis. In: Hendricks B.P, editor. Agricultural researche updates volume 1. (p 1-50). Hauppauge, New York: Nova Science Publishers, Inc.

2. Commission Decision 1995/1442/EC, 1995 of 26 June 1995, amending of Annexes I, II, III and IV to Regulation (ECC) No 2377/90, laying down a Community Procedure for the establishment of maximum residue limits of veterinary medicinal products in foodstuffs of animal origin. Off. J. Eur. Union, L143;26-30.

3. Commission Decision 2003/181/EC, 13 March 2003, amending decision 2002/657/EC as regards the setting of minimum performance limits (MRPLs) for certain residues in food animal origin, Off. J. Eur. Union, L71/17, 2003.

4. Turkish Food Codex. 2012/23856.

5. European Food Safety Authority (2015). Scientific opinion on nitrofurans and their metabolites in food. EFSA Journal 2015, 13(6): 4140.

6. Harry S.V., George W.H. (1981). Highly specific and sensitive detection method for nitrofurans by thinlayer chromatography. J Chromatogr A, 208 (1), 161-163.

http://dx.doi.org/10.1016/S0021-9673(00)87980-7
7. Barbosa J., Moura S., Barbosa R., Ramos F. Silveria M.I.N. (2007). Determination of nitrofurans in animal feeds by liquid chromatography-UV photodiode array detection and liquid chromatography-ionspray tandem mass- spectrometry. Anal Chim Acta, 586, 359-365.

http://dx.doi.org/10.1016/j.aca.2006.11.053 PMid:17386735

8. McCracken R.J., Kennedy D.G. (1997). Determination of furazolidone in animal feeds chromatography with UV and thermospray mass detection. J Chromatogr A, 771, 349-354. http://dx.doi.org/10.1016/S0021-9673(97)00178-7

9. Cooper K.M., Mulder P.P.J., Van Rhijn J.A., Kovacsics L., Mccracken R.J., Young P.B. Kennedy D.G. (2005). Depletion of four nitrofuran antibiotics and their tissue-bound metabolites in porcine tissues and determination using LC-MS/MS and HPLC-UV. Food Addit Contam, 22(5): 406-414. http://dx.doi.org/10.1080/02652030512331385218 PMid:16019811

10. Rodziewicz L. (2008). Determination of nitrofuran metabolites in milk by liquid chromatographyelectrospray ionization tandem mass spectrometry. Journal of Chromatography B, 864 156-160. http://dx.doi.org/10.1016/j.jchromb.2008.01.008 PMid:18280226

11. Mottier P., Khong S.P., Gremaud E., Richoz J., Delatour T., Goldman T Guy P.A. (2005). Quantitative determination of four nitrofuran metabolites in meat by isotope dilution liquid chromatographyelectrospray ionisation-tandem mass spectrometry. J Chromatogr A, 1067 85-91.

http://dx.doi.org/10.1016/j.chroma.2004.08.160

12. Szilagyi S., Calle B. (2006). Development and validation of an analytical method for the determination of semicarbazide in fresh egg and in egg powder based on the use of liquid chromatography tandem mass spectrometry Analytica Chimica Acta, 572, 113-120.

http://dx.doi.org/10.1016/j.aca.2006.05.012

PMid:17723467

13. Commission Decision 2003/181/EC, 13 March 2003, amending decision 2002/657/EC as regards the setting of minimum performance limits (MRPLs) for certain residues in food animal origin, Off. J. Eur. Union, L71/17, 2003. 